Marquette University

e-Publications@Marquette

School of Dentistry Faculty Research and

Publications

Dentistry, School of

9-1-2016

Edge Chipping Resistance and Flexural Strength of Polymer Infiltrated Ceramic Network and Resin Nanoceramic Restorative Materials

Renos Argyrou

Marquette University

Geoffrey A. Thompson

Marquette University, geoffrey.thompson@marquette.edu

Seok-Hwan Cho

Marquette University, seokhwan.cho@marquette.edu

David W. Berzins

Marquette University, david.berzins@marquette.edu

Accepted version. The Journal of Prosthetic Dentistry, Vol. 116, No. 3 (September 2016): 397-403.

DOI. (C) 2016 Springer-Verlag Berlin Heidelberg. Used with permission. 


\title{
Edge Chipping Resistance and Flexural Strength of Polymer Infiltrated Ceramic Network and Resin Nanoceramic Restorative Materials
}

\author{
Renos Argyrou \\ Graduate Prosthodontics, \\ Marquette University School of Dentistry, \\ Milwaukee, WI \\ Geoffrey A. Thompson \\ Department of General Dental Sciences, School of Dentistry, \\ Marquette University, \\ Milwaukee, WI \\ Seok-Hwan Cho \\ Department of General Dental Sciences, School of Dentistry, \\ Marquette University, \\ Milwaukee, WI \\ David W. Berzins \\ Department of General Dental Sciences, School of Dentistry, \\ Marquette University, \\ Milwaukee, WI
}


NOT THE PUBLISHED VERSION; this is the author's final, peer-reviewed manuscript. The published version may be accessed by following the link in the citation at the bottom of the page.

\begin{abstract}
Statement of problem: Two novel restorative materials, a polymer infiltrated ceramic network (PICN) and a resin nanoceramic (RNC), for computer-assisted design and computer-assisted manufacturing (CAD-CAM) applications have recently become commercially available. Little independent evidence regarding their mechanical properties exists to facilitate material selection.
\end{abstract}

Purpose: The purpose of this in vitro study was to measure the edge chipping resistance and flexural strength of the PICN and RNC materials and compare them with 2 commonly used feldspathic ceramic (FC) and leucite reinforced glass-ceramic (LRGC) CAD-CAM materials that share the same clinical indications.

Material and methods: PICN, RNC, FC, and LRGC material specimens were obtained by sectioning commercially available CAD-CAM blocks. Edge chipping test specimens ( $n=20 /$ material) were adhesively attached to a resin substrate before testing. Edge chips were produced using a 120-degree, sharp, conical diamond indenter mounted on a universal testing machine and positioned 0.1 to $0.7 \mathrm{~mm}$ horizontally from the specimen's edge. The chipping force was plotted against distance to the edge, and the data were fitted to linear and quadratic equations. One-way ANOVA determined intergroup differences $(a=.05)$ in edge chipping toughness. Beam specimens $(n=22 /$ material) were tested for determining flexural strength using a 3-point bend test. Weibull statistics determined intergroup differences $(a=.05)$. Flexural modulus and work of fracture were also calculated, and 1-way ANOVA determined intergroup differences $(a=.05)$

Results: Significant $(P<.05)$ differences were found among the 4 CAD-CAM materials for the 4 mechanical properties. Specifically, the material rankings were edge chipping toughness: $R N C>L R G C=F C>P I C N$; flexural strength: RNC $=$ LRGC $>$ PICN $>$ FC; flexural modulus: RNC $<$ PICN $<$ LRGC $<F C$; and work of fracture: $R N C>L R G C=P I C N>F C$.

Conclusions: The RNC material demonstrated superior performance for the mechanical properties tested compared with the other 3 materials.

\title{
Clinical Implications
}

A resin nanoceramic demonstrated greater edge chipping toughness and flexural strength than other current computerassisted design and computer-assisted manufacturing restorative materials. Ultimately, the success of the resin nanoceramic material will best be judged in clinical studies.

One of the fastest evolving aspects of modern prosthodontics is computer-aided design and computer-aided manufacturing (CAD-CAM) technology. $\underline{1}, \underline{2}$ and $\underline{3}$ Among the most commonly used CAD-CAM materials, for both chairside and laboratory fabrication, are feldspathic ceramic, leucite or lithium disilicate reinforced glass-ceramic, and composite resin blocks. $\underline{4}$ and $\underline{5}$ However, competition between 
manufacturers as well as ongoing research and development is resulting in the emergence of new CAD-CAM materials with claims of superior mechanical and machining properties. $\underline{6}$ and $\underline{7}$ Dentists are faced with selecting from a large variety of CAD-CAM materials; although the clinical evidence is well established for conventional ceramic restorations, $\underline{8}$ little evidence is available in the current literature to assist in that process for newer materials.

Ceramics in general are stronger but more rigid and brittle than composite resins, while composite resins are more compliant, softer, and less abrasive toward the opposing dentition. $\underline{4}$ and $\underline{Z}$ Lost natural tooth substance would ideally be replaced with a restorative material that possesses similar physical properties and characteristics. $\underline{9}$ Several efforts to create materials that have reduced brittleness, rigidity, and hardness and superior flexibility, fracture toughness, and machinability compared with conventional ceramics have recently been reported.10, $\underline{11}$ and $\underline{12}$ For this purpose, various methods have been used to formulate ceramic and polymer or composite resin hybrid materials. $\underline{10}, \underline{11}$ and $\underline{12}$ The concept behind these materials is to combine the positive characteristics of both ceramics and composite resins into a single material.

Two hybrid materials that have recently become commercially available are described as a polymer infiltrated ceramic network material (PICN) and a resin nanoceramic material (RNC). The original indications for these materials included single anterior and posterior crowns, veneers and inlays/onlays/overlays; however, the manufacturer has stated that the RNC material is no longer indicated for crowns because of an increased rate of debonding. According to the manufacturers, the advantages of these materials compared with other CAD-CAM materials sharing some of the same indications include high strength combined with elasticity, enhanced resistance to crack propagation, decreased enamel abrasivity, fast fabrication with a higher number of milled units per milling tool, superior machinability and edge stability during milling allowing for reduced thicknesses, and finally fast and simple processing with no need for crystallization firing or glazing (http://www.3m.com/3M/en US/Dental/Products/LavaUltimate/ and www.vita-zahnfabrik.com/en/VITA-ENAMIC24970,27568.html).

Journal of Prosthetic Dentistry, Vol 116, No. 3 (September 2016): pg. 397-403. DOI. This article is (C) Elsevier and permission has been granted for this version to appear in e-Publications@Marquette. Elsevier does not grant permission for this article to be further copied/distributed or hosted elsewhere without the express permission from Elsevier. 
Research evaluating the clinical longevity of restorations has shown that chipping is a major cause of failure. $\underline{13}$ and $\underline{14}$ Chipping may also occur at a restoration's margin during the milling process. $\underline{15}$ Specifically, hoop stresses can form major cracks that start from the chipped margin areas and eventually lead to catastrophic restoration failure. $\underline{16}$ As a response to chipping being a clinical issue, the edge chipping test is emerging as a new tool to characterize dental restorative materials. $\frac{17}{17}$ For this test, chips are formed by advancing an indenter into a material near an edge with commercial edge-chipping machines or a customized assembly on a universal testing machine. $\underline{17}$ This type of testing can be performed on both layered and monolithic ceramic materials. $\frac{17}{}$ The load at which fracture occurs depends on many factors, including the shape and sharpness of the indenter, the angle of the applied force, the angle of the specimen's edge, the distance from the edge, and the material's mechanical properties. 17 This relatively new test provides a more direct and clinically relevant indication on how resistant a material is to chipping. This is mainly because, although it is an in vitro test performed on specifically prepared specimens, the produced chips physically resemble some types produced in vivo. $\underline{15}$

Flexural strength testing is one of the most well-established methods of evaluating dental ceramic materials and is described in International Organization for Standardization (ISO) 6872 "DentistryCeramic materials." However, there are inherent limitations when trying to draw clinically relevant conclusions because of the nature of this type of testing. $\underline{18}$ and $\underline{19}$ For a 3-point flexure test, the maximum stress is generally assumed to occur at a point opposite the loading side. A stress state dependence of strength exists for materials with a high elastic modulus, while loading arrangements and testing conditions can have a pronounced effect on the results. $\underline{20}$

Even though a few reports have now been published since initiating this study, $\underline{17}, \underline{21}, \underline{22}, \underline{23}, \underline{24}, \underline{25}$ and $\underline{26}$ the selection of a ceramic/composite hybrid material is difficult. The purpose of this study was to characterize the edge chipping resistance and flexural strength of 2 ceramic/composite hybrid materials and evaluate how they compare with 2 other commonly used CAD-CAM materials that share some of the same indications, specifically a feldspathic ceramic (FC) and a leucite reinforced glass ceramic (LRGC). The goal was to 
provide clinicians with information to facilitate the clinical selection process, particularly with regard to the previously mentioned properties of these materials. The null hypotheses were that no difference would be found in the edge chipping toughness and flexural strength of the 4 materials.

\section{Material and Methods}

The CAD-CAM block materials evaluated were PICN (VITA ENAMIC; VITA Zahnfabrik), RNC (Lava Ultimate CAD-CAM Restorative; 3M ESPE), FC (VITABLOCS TriLuxe forte; VITA Zahnfabrik), and LRGC (IPS Empress CAD; Ivoclar Vivadent AG). A sample size of 40 for the edge chipping test and 22 for the flexural strength test was determined a priori to be sufficient to detect a large effect size $(\beta=.8)$ with $80 \%$ power and $5 \%$ significance.

The protocol used for the edge chipping resistance testing was similar to that of Zhang et al $\underline{27}$ that emphasized simulating occlusalsurface chipping while implementing the technical recommendations of Quinn et al. $\underline{28}$ and $\underline{29}$ Square specimens ( $n=20 /$ material) of approximate dimensions $10 \times 10 \times 2 \mathrm{~mm}$ were sectioned from commercially available CAD-CAM blocks using a diamond saw (IsoMet 11-1180-160 Low Speed Saw; Buehler Ltd) with a diamond wafering blade (IsoMet Wafering Blade 15LC; Buehler Ltd) under a load of $5 \mathrm{~N}$ and water irrigation. The 2 square faces were hand-ground using 1200-grit abrasive SiC disks (BuehlerMet II 600 [P1200]; Buehler Ltd) with water and polished with polishing cloths (PoliCloth; Buehler Ltd) and polishing paste (MicroPolish Alumina Suspension; Buehler Ltd). After polishing, the specimens were steam cleaned and dried. A custom specimen holder (Fig. 1A) was milled from steel for the purpose of this test. The holder was designed in such a way that its top face featured a $4-\mathrm{mm}$-deep $11 \times 11 \mathrm{~mm}$ central recessed area with a central 2-mm round channel running through its entire height to aid in specimen removal.

Journal of Prosthetic Dentistry, Vol 116, No. 3 (September 2016): pg. 397-403. DOI. This article is (C) Elsevier and permission has been granted for this version to appear in e-Publications@Marquette. Elsevier does not grant permission for this article to be further copied/distributed or hosted elsewhere without the express permission from Elsevier. 


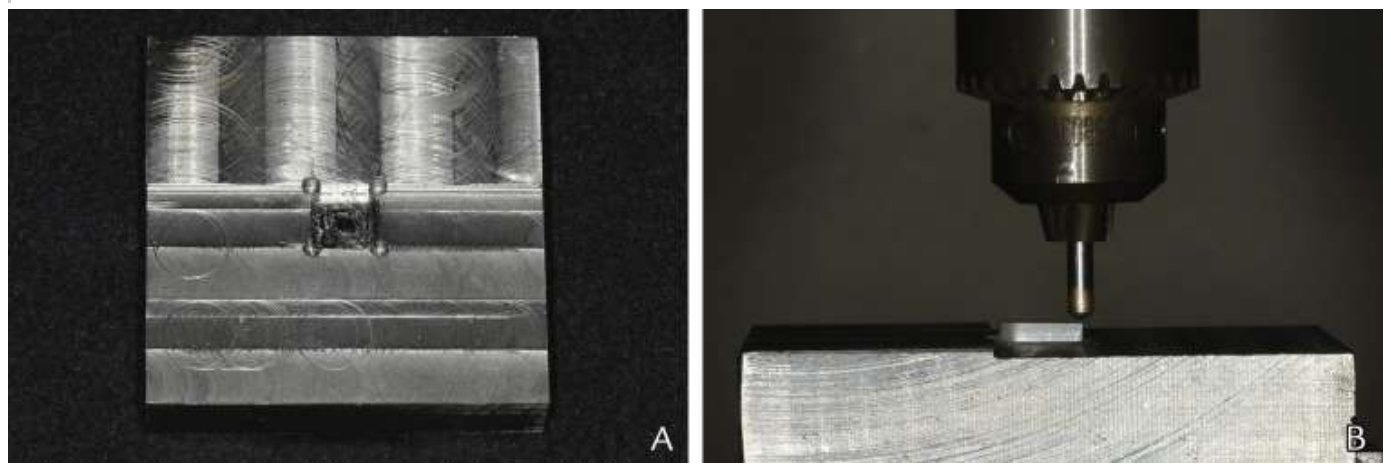

Figure 1. A, Custom holder. B, Edge chipping test assembly.

The specimen face opposite the test face was prepared for adhesive cementation according to the manufacturer's recommendations and was adhesively cemented to a flat resin ( $Z 100$; 3M ESPE) bed previously created in the recessed area of the custom holder with a dual polymerizing resin cement (Multilink Automix; Ivoclar Vivadent AG) in a standardized manner. All test specimen/resin bed complexes were removable, with the ceramic specimens being above the plane of the custom holder.

A sharp conical head indenter with a diamond tip at 120 degrees and tip sharpness under $5 \mu \mathrm{m}$ (Gilmore Diamond Tools, Inc) was fixed on a universal testing machine (Model 5500R; Instron). The custom holder with each resin bed/test specimen complex was positioned on the universal testing machine in a way that the indenter would contact the specimen 0.1 to $0.7 \mathrm{~mm}$ horizontally away from its test edge at a crosshead speed of $0.1 \mathrm{~mm} / \mathrm{min}$ (Fig. 1B). Two edge chipping tests were performed for each specimen, and the maximum loads $(N)$ causing the edge of the specimen to spall were recorded. A new indenter was used every 20 indents. The indents that resulted in incomplete spalling of the specimen's test edge or spalling that extended all the way to the resin bed were not included for further analysis.

After completion of the edge chipping, each resin bed/test specimen complex was repositioned on the custom holder, and the distance of the indenter point of contact to the specimen's test edge was measured using a travelling microscope (TM-505 Microscope; Mitutoyo Corp). Multiple approaches have been used to analyze edge 
chipping data and 2 were used in this research. The first approach plotted chipping force versus distance with the slope of the fitted line equal to edge toughness, a more easily understood parameter. Mathematically, this is represented as $F=T_{E} \times d$, where $F$ is the chipping force in newtons, $d$ is the distance of the chip from the edge in $\mathrm{mm}$, and $T_{E}$ is the edge toughness in $\mathrm{N} / \mathrm{mm}$. The second approach plotted chipping force versus distance and fit the data to a quadratic equation, $F=a_{1} d+a_{2} d^{2}$, proposed by Quinn et al. $\underline{29}$ This quadratic function has provided a good fit for a variety of brittle dental materials and relates indentation energy to the fracture $\left(a_{1}\right.$ term) and deformation ( $a_{2}$ term) processes. $\stackrel{29}{ }$ To fit both $\mathrm{F}=\mathrm{T}_{\mathrm{E}} * \mathrm{~d}$ and $\mathrm{F}=\mathrm{a}_{1} \mathrm{~d}+\mathrm{a}_{2} \mathrm{~d}^{2}$, a regression analysis with intercepts of 0 was used. Furthermore, the coefficients $T_{E}, a_{1}$, and $a_{2}$ were allowed to change by introducing dummy variables.

Hypotheses regarding these coefficients were tested using $t$ tests, with Bonferroni corrections used to remove the effect of multiplicity of the hypotheses $(a=.05)$.

Rectangular beam specimens ( $n=22 /$ material) of approximate dimensions $18 \times 4 \times 1.2 \mathrm{~mm}$ were sectioned from the commercially available CAD-CAM blocks with a diamond saw under water irrigation. All specimen surfaces were hand ground using 1200-grit SiC abrasive disks with water and polished with polishing cloths with polishing paste. After polishing, the specimens were steam cleaned and dried, and their dimensions were measured using a digital micrometer (MDCMX Series; Mitutoyo Corp). Next, a 3-point flexure test was performed on a universal testing machine with a support span of $15 \mathrm{~mm}$ and crosshead speed of $0.5 \mathrm{~mm} / \mathrm{min}$.

The fracture loads were recorded for each specimen. Flexural strength and elastic modulus were calculated for each specimen using the following equations: $\sigma_{\mathrm{f}}=3 \mathrm{~F} \mathrm{~L} /\left(2 \mathrm{~B} \mathrm{H}^{2}\right)$, where $\sigma_{\mathrm{f}}$ is the flexural strength in $\mathrm{MPa}, \mathrm{F}$ is the load at fracture in newtons, $\mathrm{L}$ is the distance between the supports in $\mathrm{mm}, \mathrm{B}$ is the width of the specimen in $\mathrm{mm}$, and $\mathrm{H}$ is the height of the specimen in $\mathrm{mm}$ and $\mathrm{E}=\Delta \mathrm{F} \mathrm{L} /\left(4 \mathrm{~B} \mathrm{H}^{3} \Delta \mathrm{D}\right)$, where $\mathrm{E}$ is the elastic or flexural modulus in $\mathrm{GPa}, \Delta \mathrm{F}$ is the change in load value $(\mathrm{N})$ in the linear portion of the load versus deflection curve, and $\Delta D$ is the corresponding change in deflection in $\mathrm{mm}$ (in reference to $\Delta \mathrm{F})$. Work of fracture ( $\mathrm{mJ}$ ) was also calculated by computing the area under the flexural load versus deflection curve. Weibull statistics

Journal of Prosthetic Dentistry, Vol 116, No. 3 (September 2016): pg. 397-403. DOI. This article is (C) Elsevier and permission has been granted for this version to appear in e-Publications@ Marquette. Elsevier does not grant permission for this article to be further copied/distributed or hosted elsewhere without the express permission from Elsevier. 
were used to determine intergroup differences $(a=.05)$ regarding flexural strength and presented as likelihood contour plots. The likelihood contour method is described elsewhere ${ }^{30}$; however, simply stated, a horizontal slice is made in the 3-dimensional contour plot of the Weibull distributions being compared at equal likelihoods. The plot has the $95 \%$ confidence bounds of the estimate for the Weibull shape parameter (beta) on the $\mathrm{Y}$-axis and the $95 \%$ confidence bounds for the estimate of the characteristic strength (alpha) on the X-axis. If confidence bounds intersect, Weibull distributions are not significantly different. Flexural strength data were fitted using median ranks regression with a reduced biasing adjustment. A 1-way ANOVA and post hoc tests (Tukey-Kramer HSD) were used to evaluate intergroup differences for flexural modulus and work of fracture $(a=.05)$.

\section{Results}

Figure 2 is a plot of chipping force versus distance from the specimen edge for each material. Using the linear regression with 0 intercept, the edge toughness of the materials were $120 \mathrm{~N} / \mathrm{mm}$ for PICN, $275 \mathrm{~N} / \mathrm{mm}$ for RNC, $179 \mathrm{~N} / \mathrm{mm}$ for FC, and $169 \mathrm{~N} / \mathrm{mm}$ for LRGC. Comparing the slopes by using $t$ tests with Bonferroni corrections to multiple hypotheses exhibited significantly different edge toughness when comparing all materials together $(P<.05)$. When testing individually, no significant difference was found between the LRGC and FC materials $(P>.05)$, although a significant difference was found between the LRGC and FC materials compared with the PICN material $(P<.05)$, with the LRGC and FC materials being superior. Figure 2 also displays the quadratic equations for fitting the chipping force to distance for each material. The adjusted $\mathrm{R}^{2}$ values showed a greater fit using the quadratic equation compared with the linear equation. Examination of the $a_{1}$ term associated with the fracture process displayed a greater value for the RNC material, whereas the $a_{2}$ term associated with deformation was greatest in the FC material.

Journal of Prosthetic Dentistry, Vol 116, No. 3 (September 2016): pg. 397-403. DOI. This article is (C) Elsevier and permission has been granted for this version to appear in e-Publications@Marquette. Elsevier does not grant permission for this article to be further copied/distributed or hosted elsewhere without the express permission from Elsevier. 

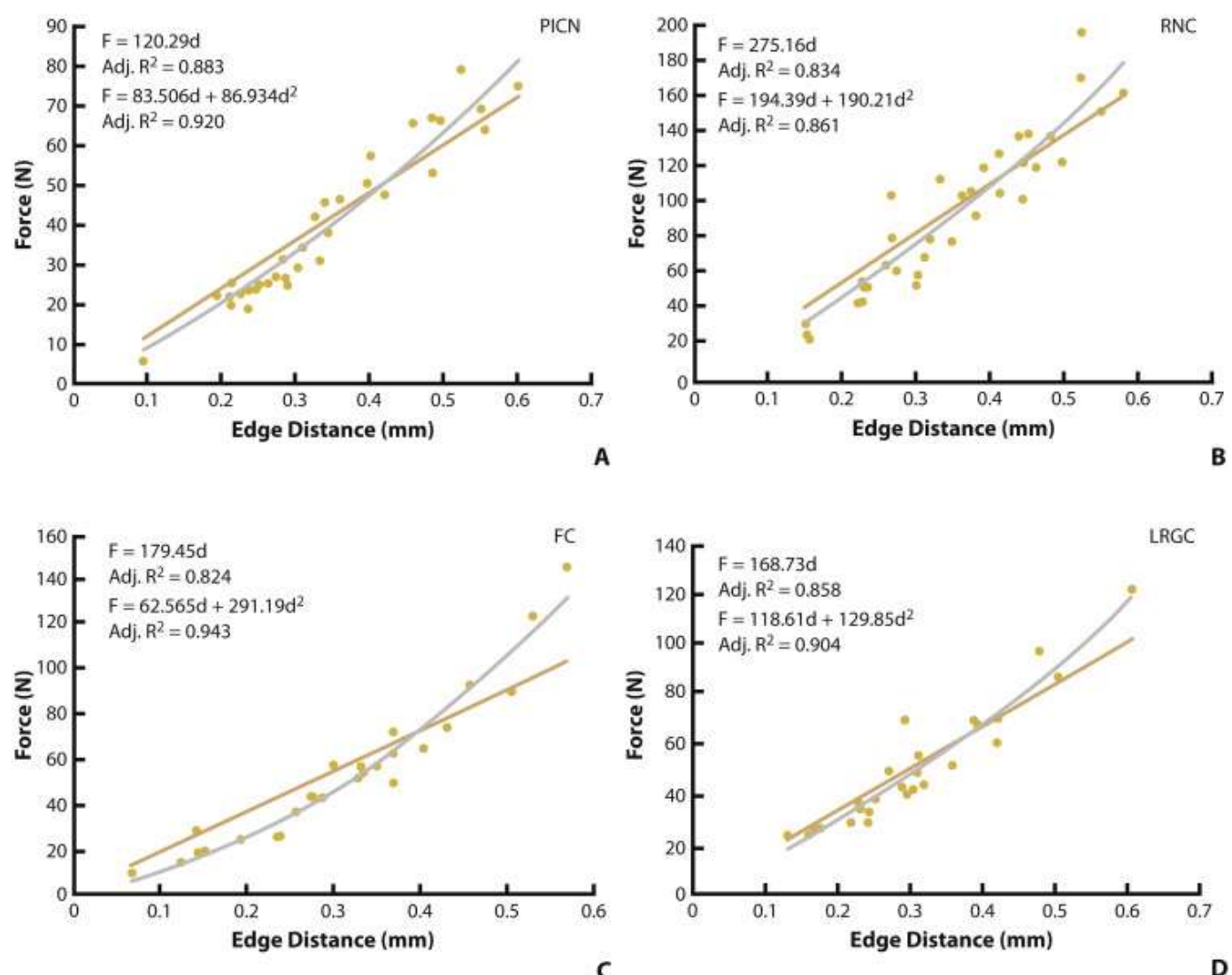

Figure 2. Chipping force versus edge distance. A, Polymer infiltrated ceramic network material, PICN. B, Resin nanoceramic material, RNC. C, Feldspathic ceramic, FC. D, Leucite reinforced glass-ceramic, LRGC.

Flexural strength, modulus of elasticity, work, characteristic strength, and Weibull modulus values for the 4 materials are presented in Table 1. A comparison of the flexural strength curves is presented in Figure 3, showing the RNC material to behave qualitatively differently than the 3 other materials. Figure $4 \mathrm{~A}$ shows a 2-parameter Weibull plot of the cumulative distribution function (CDF) occurrence percentage versus flexural strength, while Figure $4 \mathrm{~B}$ displays a likelihood contour plot of characteristic strength versus Weibull modulus.

Table 1. Flexural strength testing results, mean (standard deviation)

$\begin{array}{cccccc}\text { Group } & \begin{array}{c}\text { Flexural } \\ \text { Strength } \\ \text { (MPa) }\end{array} & \begin{array}{c}\text { Modulus of } \\ \text { Elasticity } \\ \text { (GPa) }\end{array} & \begin{array}{c}\text { Work } \\ (\mathbf{m J})\end{array} & \begin{array}{c}\text { Weibull Characteristic } \\ \text { Strength (MPa) }\end{array} & \begin{array}{c}\text { Weibull } \\ \text { Modulus }\end{array} \\ \text { PICN } & 124(8)^{\mathrm{B}} & 27.26(0.67)^{\mathrm{C}} & \begin{array}{l}8.36 \\ (1.01)^{\mathrm{B}}\end{array} & 127 & 18.27\end{array}$


NOT THE PUBLISHED VERSION; this is the author's final, peer-reviewed manuscript. The published version may be accessed by following the link in the citation at the bottom of the page.

$\begin{array}{lcclcc}\text { Group } & \begin{array}{r}\text { Flexural } \\ \text { Strength } \\ \text { (MPa) }\end{array} & \begin{array}{c}\text { Modulus of } \\ \text { Elasticity } \\ \text { (GPa) }\end{array} & \begin{array}{c}\text { Work } \\ (\mathbf{m J})\end{array} & \begin{array}{c}\text { Weibull Characteristic } \\ \text { Strength (MPa) }\end{array} & \begin{array}{c}\text { Weibull } \\ \text { Modulus }\end{array} \\ \text { RNC } & 170(13)^{\mathrm{A}} & 13.33(0.12)^{\mathrm{D}} & \begin{array}{l}41.23 \\ (7.90)^{\mathrm{A}}\end{array} & 176 & 15.39 \\ \text { FC } & 120(6)^{\mathrm{C}} & 43.01(1.51)^{\mathrm{A}} & \begin{array}{l}4.68 \\ (0.42)^{\mathrm{C}}\end{array} & 122 & 22.58 \\ & 159(18)^{\mathrm{A}} & 40.78(2.03)^{\mathrm{B}} & \begin{array}{l}8.60 \\ (2.07)^{\mathrm{B}}\end{array} & 167 & 11.07\end{array}$

PICN, polymer infiltrated ceramic network; RNC, resin nanoceramic; FC, feldspathic ceramic; LRGC, leucite reinforced glass-ceramic. Different superscript letters indicate different means within same column $(P<.05)$.

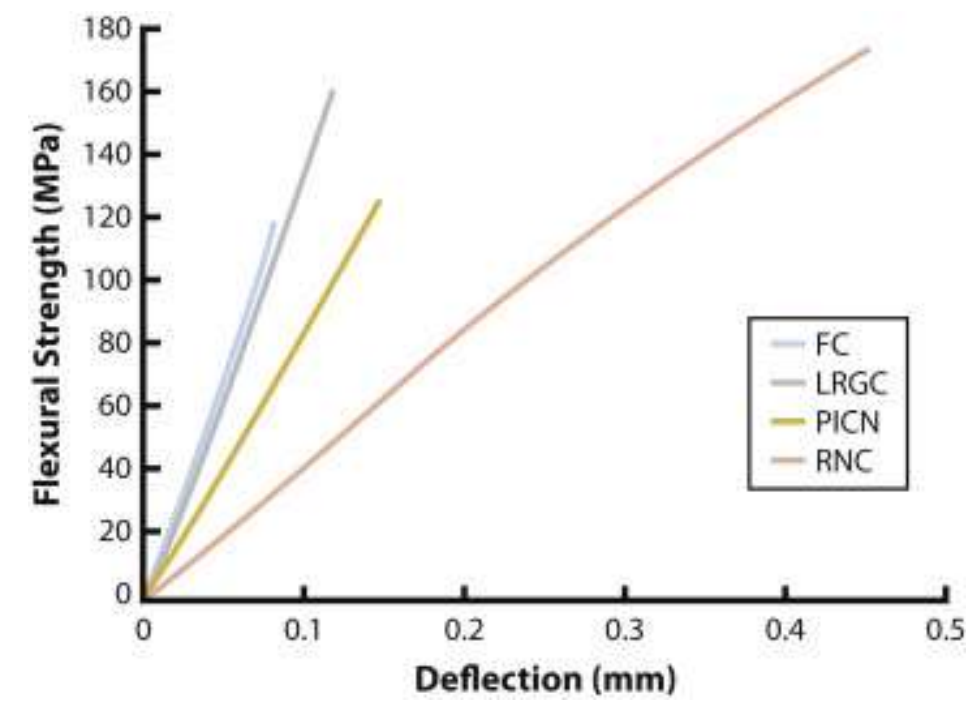

Figure 3. Flexural strength comparison.

Journal of Prosthetic Dentistry, Vol 116, No. 3 (September 2016): pg. 397-403. DOI. This article is (C) Elsevier and permission has been granted for this version to appear in e-Publications@Marquette. Elsevier does not grant permission for this article to be further copied/distributed or hosted elsewhere without the express permission from Elsevier. 
NOT THE PUBLISHED VERSION; this is the author's final, peer-reviewed manuscript. The published version may be accessed by following the link in the citation at the bottom of the page.
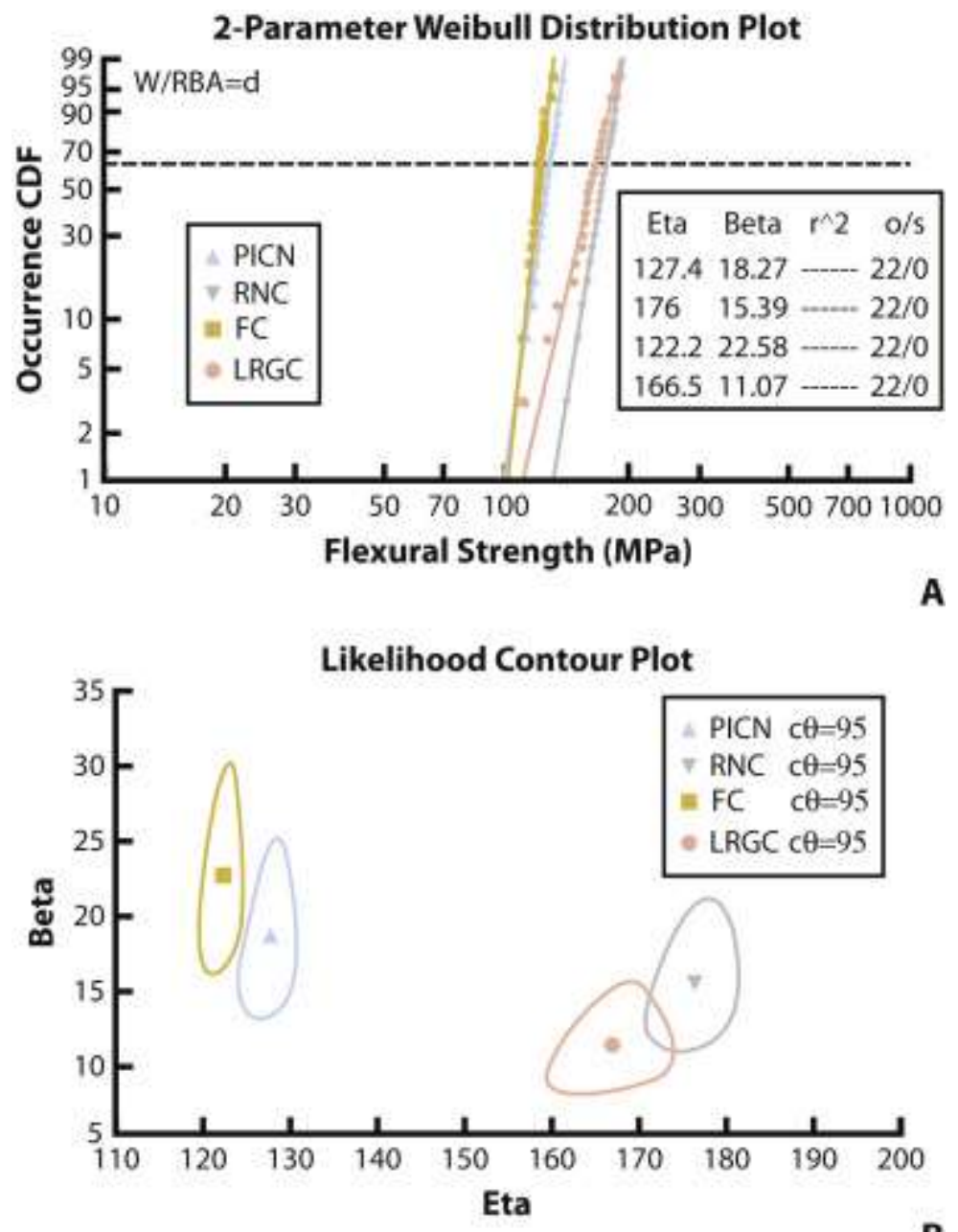

B

Figure 4. A, Two parameter Weibull plot. B, Weibull likelihood contour plot. Eta, characteristic strength; beta, Weibull modulus.

The Weibull statistics revealed no significant difference in flexural strength between the RNC material, which had the highest mean flexural strength value, and the LRGC material $(P>.05)$ ( Fig. 4B). However, a significant difference was found between the RNC and LRGC materials compared with the FC and PICN materials $(P<.05)$. Moreover, there was a significant difference between the FC and the PICN material $(P<.05)$ with the PICN material being superior ( Fig. 4B). With respect to modulus of elasticity, 1-way ANOVA followed by a Tukey-Kramer HSD post hoc test revealed a significant difference among all the tested materials $(P<.05)$ with the following ranking: RNC $<$ PICN $<$ LRGC $<$ FC. Regarding work of fracture, 1 -way ANOVA followed by a Tukey-Kramer HSD post hoc test revealed a significant difference between the RNC material, which had the highest

Journal of Prosthetic Dentistry, Vol 116, No. 3 (September 2016): pg. 397-403. DOI. This article is (C) Elsevier and permission has been granted for this version to appear in e-Publications@Marquette. Elsevier does not grant permission for this article to be further copied/distributed or hosted elsewhere without the express permission from Elsevier. 
work value, and the other materials $(P<.05)$. No difference was found between the PICN and the LRGC material, but they had significantly greater work of fracture than the FC material $(P<.05)$.

\section{Discussion}

Both null hypotheses were rejected, in that significant differences in both edge chipping toughness and flexural strength were found between materials.

Edge chipping resistance is a relatively new mechanical test for evaluating dental materials, although some comparative data are available. Quinn $\underline{17}$ showed the RNC material to have superior edge chipping resistance followed by the LRGC material, a feldspathic porcelain, and finally the PICN material. His rankings are in agreement with the results of the present study, although the $a_{1}$ and $a_{2}$ coefficients are not always comparable. Reconciliation of this discrepancy is problematic because the same indenter type/vendor source was used; differences in loading rate and substrate are possible sources of the variance. The RNC material possessed more than double the edge chipping toughness compared with the PICN material; this difference may be attributed to compositional and microstructural complexities.

The edge chipping resistance test protocol used had several limitations. Despite the standardization of many steps, slight variations may have occurred in sample dimensions (although dimensional standard deviations were less than $0.1 \mathrm{~mm}$ ), polishing, and adhesive luting. Furthermore, the specimen's tested edge may have varied somewhat from a perfect 90 -degree edge. Some indents resulted in incomplete spalling of the specimen's test edge or spalling that extended all the way to the resin bed; each mode was subsequently excluded from further analysis. Measuring the exact distance of the indenter point of contact to the specimens' test edge was not always straightforward and had an estimated accuracy of $10 \mu \mathrm{m}$. Natural dentition and dental restorations are of course different from the sharp conical indenter used for the testing, and the oral environment was also not replicated. Finally, although recommendations for edge chipping testing have been developed, a specification has not yet been established. 17 
All the tested materials demonstrated a flexural strength greater than $100 \mathrm{MPa}$, thereby satisfying the requirements of ISO 6872 for their clinical indications. For the RNC material, the manufacturer reports a flexural strength of $200 \mathrm{MPa}$, which is $15 \%$ higher than the mean value measured in the present study. For the PICN material, the manufacturer advertises a flexural strength of 150 to $160 \mathrm{MPa}$, which is $22 \%$ higher than the mean value measured. Dimensions of the flexure beams, specimen preparation, distance between support spans of the flexure apparatus, environment, and the loading rate all affect flexure strength, and those factors, in regard to the manufacturers results, are unknown. The reported modulus of elasticity of $30 \mathrm{GPa}$ and Weibull modulus of 20 are comparable with the values found in the present study for PICN. Regarding the Weibull modulus, all of the materials demonstrated relatively high values, indicating high reliability, with the FC material having the highest modulus. Coldea et al $\underline{21}$ measured the strength degradation of a range of dental CADCAM ceramic materials and found an initial flexural strength of 152 MPa and modulus of elasticity of 35.48 GPa for the PICN material. These values are approximately $18 \%$ and $23 \%$ higher than the values found in this study. However, the modulus of elasticity was determined by the impulse excitation of vibration technique. $\underline{21}$

The flexural strength test protocol had its limitations too. The length of the test bars could not conform to ISO 6872 because of the limiting size of the commercially available CAD-CAM blocks. Additionally, this was an in vitro test performed in a controlled environment. Clinically, restorations do not usually fail in a single load to failure manner but rather fail because of fatigue in the wet oral environment. Inherently, this type of testing cannot have direct clinical implications. $\frac{18}{}$ However, the results of this test provide an accurate comparison of the 4 materials because of the standardization of the specimens and testing and the existence of a controlled laboratory environment. Determining the material mechanical properties is an essential first step to understanding the behavior of the materials used in restorative dentistry. $\underline{19}$

The PICN and RNC materials evaluated represent hybrid ceramic/polymer materials aimed at combining the advantages of both classes of materials. However, more research into other properties as well as the microstructure and strengthening mechanisms appears

Journal of Prosthetic Dentistry, Vol 116, No. 3 (September 2016): pg. 397-403. DOI. This article is (C) Elsevier and permission has been granted for this version to appear in e-Publications@Marquette. Elsevier does not grant permission for this article to be further copied/distributed or hosted elsewhere without the express permission from Elsevier. 
warranted. Ultimately, the success of the materials will best be judged through prospective, long-term clinical studies. Already, however, as mentioned, the manufacturer of the RNC material no longer recommends its application as a crown because of an unacceptable debonding rate, illustrating that favorable in vitro properties do not always correlate with clinical success.

\section{Conclusions}

Within the limitations of this study, the following conclusions may be drawn:

1. The RNC material demonstrated superior edge chipping toughness, flexural strength, and work of fracture compared with the PICN, FC, and LRGC.

2. The PICN material demonstrated the lowest edge chipping toughness, while it ranked within the middle with respect to flexural strength, modulus of elasticity, and work of fracture.

\section{Acknowledgments}

The authors thank Drs Naveen Bansal and Kate Sherman for the statistical analyses, the MU Engineering Discovery Learning Laboratory for use of the traveling microscope, and Mr Tom Silman for fixture fabrication.

\section{References}

${ }^{1}$ W.H. Mörmann. The evolution of the CEREC system. J Am Dent Assoc, 137 Suppl (2006), pp. 7S-13S

${ }^{2}$ G. Davidowitz, P.G. Kotick. The use of CAD/CAM in dentistry. Dent Clin North Am, 55 (2011), pp. 559-570

3 T. Miyazaki, Y. Hotta, J. Kunii, S. Kuriyama, Y. Tamaki. A review of dental CAD/CAM: current status and future perspectives from 20 years of experience. Dent Mater J, 28 (2009), pp. 44-56

${ }^{4} \mathrm{R}$. Giordano. Materials for chairside CAD/CAM-produced restorations. J Am Dent Assoc, 137 Suppl (2006), pp. 14S-21S

${ }^{5}$ D.J. Fasbinder. Chairside CAD/CAM: an overview of restorative material options. CompendContin Educ Dent, 33 (2012), p. 50 52-8

6I. Denry, J.R. Kelly. Emerging ceramic-based materials for dentistry. J Dent Res, 93 (2014), pp. 1235-1242

7N.D. Ruse, M.J. Sadoun. Resin-composite blocks for dental CAD/CAM applications. J Dent Res, 93 (2014), pp. 1232-1234

Journal of Prosthetic Dentistry, Vol 116, No. 3 (September 2016): pg. 397-403. DOI. This article is (C) Elsevier and permission has been granted for this version to appear in e-Publications@Marquette. Elsevier does not grant permission for this article to be further copied/distributed or hosted elsewhere without the express permission from Elsevier. 
NOT THE PUBLISHED VERSION; this is the author's final, peer-reviewed manuscript. The published version may be accessed by following the link in the citation at the bottom of the page.

${ }^{8}$ A. Della Bona, J.R. Kelly. The clinical success of all-ceramic restorations. J Am Dent Assoc, 139 Suppl (2008), pp. 8S-13S

${ }^{9}$ F.J. Burke, A.C. Shortall, E.C. Combe, T.C. Aitchison. Assessing restorative dental materials: I. Test methods and assessment of results. Dent Update, 29 (2002), pp. 188-194

${ }^{10} \mathrm{~L} . \mathrm{H}$. He, M. Swain. A novel polymer infiltrated ceramic dental material. Dent Mater, 27 (2011), pp. 527-534

11 M. Petrini, M. Ferrante, B. Su. Fabrication and characterization of biomimetic ceramic/polymer composite materials for dental restoration. Dent Mater, 29 (2013), pp. 375-381

12].F. Nguyen, D. Ruse, A.C. Phan, M.J. Sadoun. High-temperature-pressure polymerized resin-infiltrated ceramic networks. J Dent Res, 93 (2014), pp. 62-67

$\underline{13}$ S.D. Heintze, V. Rousson. Survival of zirconia- and metal-supported fixed dental prostheses: a systematic review. Int J Prosthodont, 23 (2010), pp. 493-502

${ }_{14}^{14}$. Kern, M. Sasse, S. Wolfart. Ten-year outcome of three-unit fixed dental prostheses made from monolithic lithium disilicate ceramic. J Am Dent Assoc, 143 (2012), pp. 234-240

15 E.A. Tsitrou, S.E. Northeast, R. van Noort. Brittleness index of machinable dental materials and its relation to the marginal chipping factor. J Dent, 35 (2007), pp. 897-902

16I. Denry. How and when does fabrication damage adversely affect the clinical performance of ceramic restorations? Dent Mater, 29 (2013), pp. 85-96

17G.D. Quinn. On edge chipping testing and some personal perspectives on the state of the art of mechanical testing. Dent Mater, 31 (2015), pp. 26-36

18].R. Kelly, P. Benetti, P. Rungruanganunt, A.D. Bona. The slippery slope: critical perspectives on in vitro research methodologies. Dent Mater, 28 (2012), pp. 41-51

${ }^{19} \mathrm{~K} . J$. Anusavice, K. Kakar, N. Ferree. Which mechanical and physical testing methods are relevant for predicting the clinical performance of ceramic-based dental prostheses? Clin Oral Implants Res, 18 Suppl 3 (2007), pp. 218-231

20].R. Kelly. Perspectives on strength. Dent Mater, 11 (1995), pp. 103-110

$\underline{21}$ A. Coldea, M.V. Swain, N. Thiel. Hertzian contact response and damage tolerance of dental ceramics. J Mech Behav Biomed Mater, 34 (2014), pp. 124-133

${ }_{22}$ A. Della Bona, P.H. Corazza, Y. Zhang. Characterization of a polymerinfiltrated ceramic-network material. Dent Mater, 30 (2014), pp. 564569

Journal of Prosthetic Dentistry, Vol 116, No. 3 (September 2016): pg. 397-403. DOI. This article is (C) Elsevier and permission has been granted for this version to appear in e-Publications@Marquette. Elsevier does not grant permission for this article to be further copied/distributed or hosted elsewhere without the express permission from Elsevier. 
NOT THE PUBLISHED VERSION; this is the author's final, peer-reviewed manuscript. The published version may be accessed by following the link in the citation at the bottom of the page.

$\underline{23} \mathrm{H}$. El-Damanhoury, R. Haj-Ali, J. Platt. Fracture resistance and microleakage of endocrowns utilizing three CAD-CAM blocks. Oper Dent, 40 (2015), pp. 201-210

${ }^{24}$ A.C. Johnson, A. Versluis, D. Tantbirojn, S. Ahuja. Fracture strength of CAD/CAM composite and composite-ceramic occlusal veneers. J Prosthodont Res, 58 (2014), pp. 107-114

${ }_{25}^{25}$. Awada, D. Nathanson. Mechanical properties of resin-ceramic CAD/CAM restorative materials. J Prosthet Dent, 114 (2015), pp. 587-593

26 B.T. Leung, J.K. Tsoi, J.P. Matinlinna, E.H. Pow. Comparison of mechanical properties of three machinable ceramics with an experimental fluorophlogopite glass ceramic. J Prosthet Dent, 114 (2015), pp. 440446

27Y. Zhang, J.J. Lee, R. Srikanth, B.R. Lawn. Edge chipping and flexural resistance of monolithic ceramics. Dent Mater, 29 (2013), pp. 12011208

${ }^{28}$ G.D. Quinn, A.A. Giuseppetti, K.H. Hoffman. Chipping fracture resistance of dental CAD/CAM restorative materials: part I. Procedures and results. Dent Mater, 30 (2014), pp. e99-e111

${ }^{29}$ G.D. Quinn, A.A. Giuseppetti, K.H. Hoffman. Chipping fracture resistance of dental CAD/CAM restorative materials: part 2. Phenomenological model and the effect of indenter type. Dent Mater, 30 (2014), pp. e112-e123

30 $\mathrm{R}$. Abernethy. The new Weibull handbook. (5th ed.) Dr Robert Abernethy, Publisher (2006), pp. 7-11

Supported by an American Academy of Fixed Prosthodontics Stanley D. Tylman Research Grant.

Corresponding author: Dr David W. Berzins, Marquette University School of Dentistry, 1801 W. Wisconsin Ave, Milwaukee, WI 53233

Journal of Prosthetic Dentistry, Vol 116, No. 3 (September 2016): pg. 397-403. DOI. This article is (C Elsevier and permission has been granted for this version to appear in e-Publications@Marquette. Elsevier does not grant permission for this article to be further copied/distributed or hosted elsewhere without the express permission from Elsevier. 